\title{
Study on safety and reliability of low- temperature tanks with perlite loose insulation during seismic events
}

\author{
Rustam Shigapov and Oleg Kovalchuk ${ }^{*}$ \\ Moscow State University of Civil Engineering, Yaroslavskoe shosse, 26, Moscow, 129337, Russia
}

\begin{abstract}
A low-temperature tank is a type of tanks, that is used to store gas products in a liquid form at constantly low temperature under relatively low pressure. There are some features in the structure of this type of tanks. The main feature is the presence of thermal insulation. One of the most frequently used variants of low-temperature tanks is the type that consists of two cylindrical vessels with loose perlite insulation in an interwall space. Usually, it is concluded that the inner vessel and outer vessel act independently of each other during seismic events, but the rightness of this assumption is hardly ever investigated. This lack of study may cause serious safety issues, provoking underestimation of seismic loads on the inner and outer vessel as well as neglecting other complex effects such as influence on the form and frequencies of excited modes of the coupled flexible tank wall and fluid motion. In this paper principal effects of loose perlite insulation and its influence on seismic behaviour of two-vessel storages are discussed.
\end{abstract}

\section{Introduction}

One of the most dangerous factors, affecting buildings and structures, is an earthquake. Among the objects of the increased level of responsibility one should highlight large storage tanks for various liquid products. Damages of these tanks can cause failures with catastrophic consequences [1-5]. The problem of providing satisfactory level of reliability and safety of these structures is directly related to the development of modern methods of calculation and analysis of its elements.

Many of the low-temperature tanks are built in the seismic-prone zones, so there is a need in providing some necessary regulations, concerning the seismic design of this type of tanks. Gas liquefaction technology is widely used in Oil and Gas Industry for transport and storage of gases, such as methane, ethane, propane, oxygen and so on. There are two ways to keep liquified gases in a liquid form - the use of high-pressure gasholders at ambient temperature, and the use of low-temperature tanks under atmospheric pressure [6]. One of the most frequently used types of low-temperature tanks is the is the type that consists of two cylindrical vessels with loose perlite insulation in an interwall space (Figure 1) [7]. Standards and codes of the Russian Federation [8,9] do not have any provisions of the

\footnotetext{
Corresponding author: Kovalchuk@mgsu.ru
} 
seismic design of the tank, except some industrial codes, such as [10]. Also, specified provisions for seismic design of low-temperature tanks placed in the American standard of A.P.I. 620 "Design and Construction of Large, Welded, Low-pressure Storage Tanks" do not contain an investigation of effects of perlite insulation on the seismic behavior of tanks. It is assumed there, that inner and outer vessels act independently, thus these vessels can be analyzed separately [11]. However, the rightness of this assumption is hardly ever investigated. Thus, the special investigation is needed to either confirm or disprove the described assumption. This paper provides the study of some static and quasi-dynamic effects of the loose insulation on the design of low-temperature tanks.

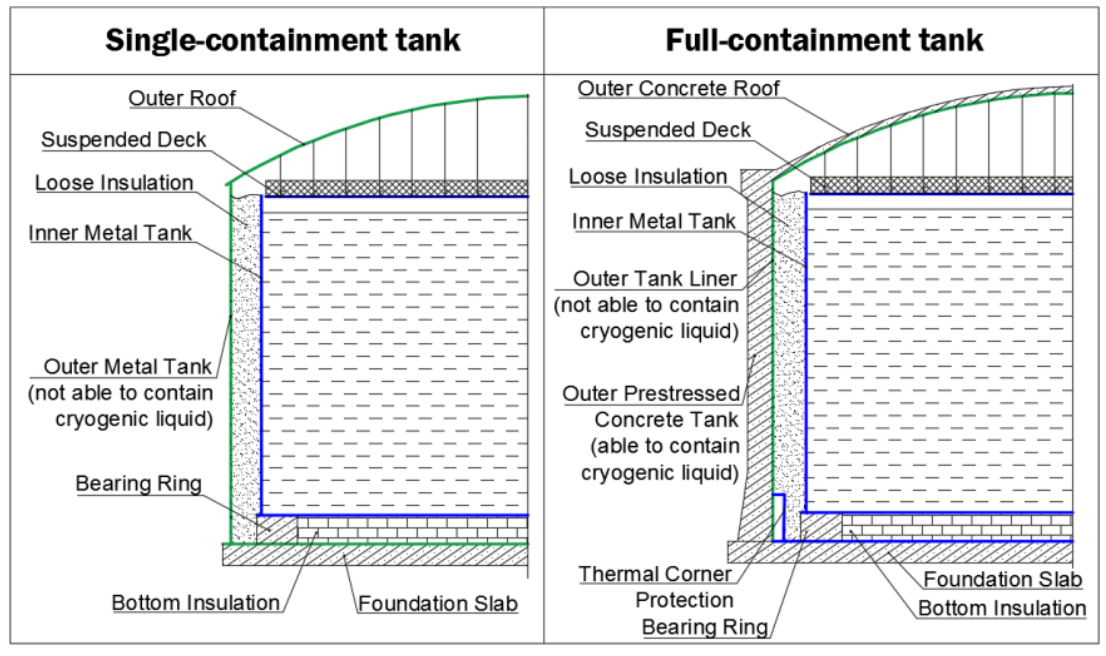

Fig. 1. Single-containment and full-containment types of low-temperature tanks

Parameters of an example full-containment tank for LNG storage with the volume of $100000 \mathrm{~m} 3$, that is used for calculation in this paper, are given in Table 1.

Table 1. Example LNG tank parameters

\begin{tabular}{|c|c|c|c|}
\hline \multicolumn{2}{|c|}{ Inner Tank Parameters } & \multicolumn{2}{|c|}{ Outer Tank Parameters } \\
\hline \multicolumn{4}{|c|}{ Radii: } \\
\hline $\mathrm{R}_{1}, \mathrm{~m}$ & 32 & $\mathrm{R}_{2}, \mathrm{~m}$ & 33 \\
\hline \multicolumn{4}{|c|}{ Heights of tank and containing liquid ${ }^{\mathrm{a}}$ : } \\
\hline $\mathrm{H}_{1}, \mathrm{~m}$ & 34.22 & $\mathrm{H}_{2}, \mathrm{~m}$ & 39 \\
\hline $\mathrm{H}_{\mathrm{L}, 1}, \mathrm{~m}$ & 32.95 & $\mathrm{H}_{\mathrm{L}, 2, \mathrm{~m}}$ & 31 \\
\hline $\mathrm{H}_{\mathrm{L}, 1} / \mathrm{R}_{1}$ & 1.03 & $\mathrm{H}_{\mathrm{L}, 1} / \mathrm{R}_{1}$ & 0.94 \\
\hline \multicolumn{4}{|c|}{ Wall thickness: } \\
\hline $\mathrm{S}_{1, \min , \mathrm{mm}}$ & 12.95 & $\mathrm{~S}_{2, \min }, \mathrm{mm}$ & 500 \\
\hline $\mathrm{S}_{1, \max }, \mathrm{mm}$ & 30.51 & $\mathrm{~S}_{2, \max }, \mathrm{mm}$ & 1000 \\
\hline $\mathrm{S}_{1, \mathrm{av}}, \mathrm{mm}$ & 21.73 & $\mathrm{~S}_{2, \mathrm{av}}, \mathrm{mm}$ & 750 \\
\hline $\mathrm{S}_{1, \mathrm{av}} / \mathrm{R}_{1}$ & 0.0007 & $\mathrm{~S}_{2, \mathrm{av}} / \mathrm{R}_{2}$ & 0.023 \\
\hline
\end{tabular}

${ }^{\mathrm{a}}$ Outer tank may contain liquid in case of inner tank failure 


\section{Effects of perlite insulation in low-temperature tanks during the operation}

Effects of loose insulation during the operation of the tank can be divided into two parts an active pressure and a reactive pressure.

Active pressure is a pressure exerted by a loose body on the tank walls due to gravity loads. Active pressure is usually calculated with the classic formula of Yansen [12], also given in [13]:

$$
p_{p, h}^{a}(z)=\rho_{p} g \frac{d_{p}}{2 \operatorname{tg}\left(\varphi_{p}\right)}\left(1-\exp \left[-\frac{2 \xi_{p} \operatorname{tg}\left(\varphi_{p}\right) z}{d_{p}}\right]\right)
$$

where $\xi_{p}$ is the lateral pressure coefficient, $d_{p}$ is the perlite body width, $\varphi_{p}$ is the angle of internal friction and $\rho_{p}$ is the perlite density. According to [14], $\xi_{p}=0,55 ; \varphi_{p}=29^{\circ}$.

However, this formula does not consider the effect of additional compaction, occurring in the loose body due to compression stresses. An investigation of perlite insulation compression in tanks is set out in the thesis [14]. A set of compression tests was held for several samples of perlite of different densities. Graphs for the densities from 58 to 130 $\mathrm{kg} / \mathrm{m}^{3}$ given there may be approximated by the formula:

$$
\frac{\rho}{\rho_{0}}=A_{1} \exp \left[B_{1} p_{p, v}^{a}\right]-\left(A_{1}-1\right) \exp \left[-100 B_{1} p_{p, v}^{a}\right]
$$

where $A_{1}$ and $B_{1}$ are functions of initial density:

$$
\begin{gathered}
A_{1}=0,2 \cdot\left(\frac{\rho_{0}}{58}\right)^{-5,5}+1,13 \\
B_{1}=0,003\left(\frac{\rho_{0}}{58}\right)^{-0,34}
\end{gathered}
$$

Therefore, it is possible to determine lateral and vertical pressures in a loose body with the integral expression:

$$
\int_{0}^{p_{p, v}^{a}} \frac{d p_{p, v}^{a}}{\left(A_{1}\left(\rho_{0}\right) e^{B_{1}\left(\rho_{0}\right) p_{p, v}^{a}}-\left(A_{1}-1\right) e^{-100 B_{1}\left(\rho_{0}\right) p_{p, v}^{a}}-\left(\frac{2 \operatorname{tg} \varphi_{0} \xi_{p}}{\rho_{0} g d_{p}}\right) p_{p, v}^{a}\right)}=\rho_{0} g z
$$

Values of active pressures and relative compaction, calculated for the example tank with perlite density, equal to $58 \mathrm{~kg} / \mathrm{m}^{3}$, are given in Figure 2 . 

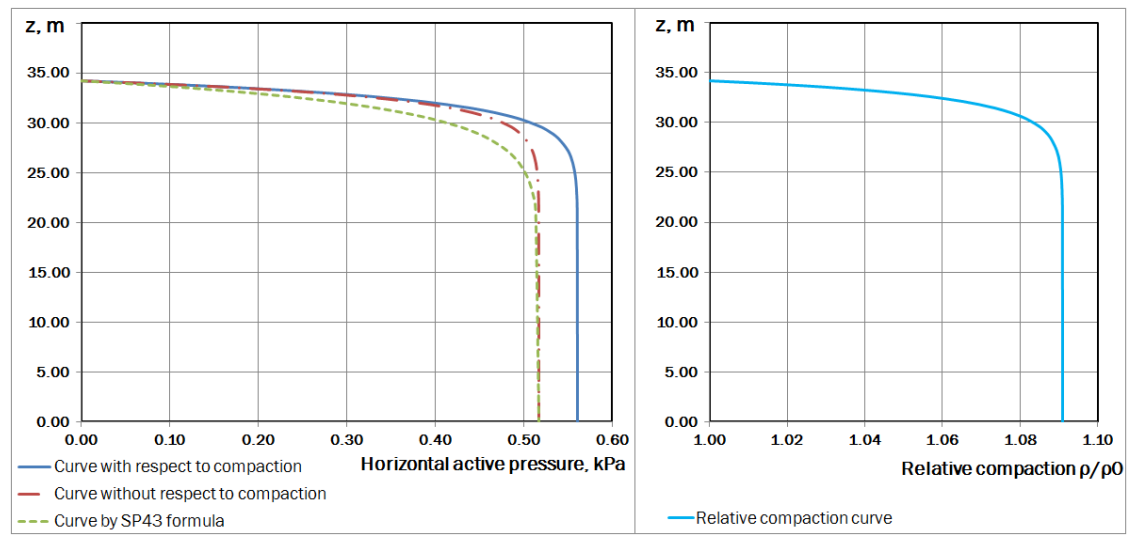

Fig. 2. Active pressure and relative compaction curves for the example tank

Passive pressure, in turn, can be estimated from "stress-strain" curves for the case of compaction without any lateral expansion. This assumption may be justified as far as vertical expansion of loose body is relatively low due to high "backfilling height to backfilling width" ratio. Density is a function of strain, thus, strain-stress can be obtained from previously described relations:

$$
\begin{gathered}
\frac{\rho}{\rho_{0}}=\frac{1}{1-\varepsilon_{p}} \\
\varepsilon_{p}=1-\frac{1}{A_{1} \exp \left[B_{1} p_{p}^{p}\right]-\left(A_{1}-1\right) \exp \left[-100 B_{1} p_{p}^{p}\right]}
\end{gathered}
$$

One can notice, that "strain-stress" function become almost linear after pressure reaches the value of $10 \mathrm{kPa}$ (Figure 3). Deformations of the loose body can be divided into two parts - irreversible deformations of the structure due to movement of grains and elastic or plastic deformations of grains. Thus, linearization of the stress-strain curve can be treated as cease of structural deformations and, consequently, loose body act as elastic body with Young modulus, approximately equal to 500-600 kPa. This, in fact, can be an important observation, because structural deformations of the loose body may cease due to various reasons, such as cyclic loadings or vibration compaction. Cyclic loadings may be related to some operational processes of low-temperature tanks, such as discharge-pouring "discharge-fill" operation, that cause thermal movements of the wall towards and away from perlite body. It is shown in [14], that structural deformations of perlite body cease after 10-16 cycles of refilling.

Therefore, we can assume that right before the start of seismic event perlite backfilling may be in two different states: an uncompacted state with the stress-strain curve, described by (7), and compacted state, acting as the elastic body with Young modulus, approximately equal to $500-600 \mathrm{kPa}$.

Strain due to movement of the wall, in fact, can cause additional compaction of perlite layers and this fact may lead to further increase of active pressure, but it can be shown, that passive pressure usually is much greater than active pressure. 

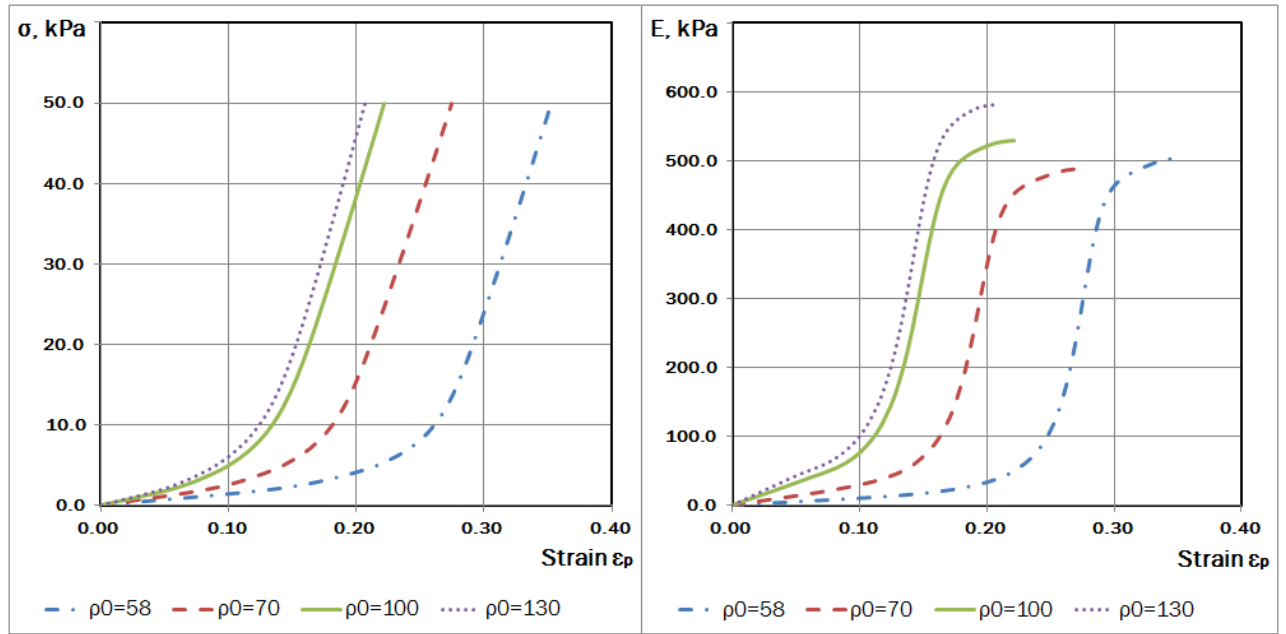

Fig. 3. Stress-strain curve and deformation modulus curve

\section{Effects of perlite insulation in low-temperature tanks during the seismic events}

\subsection{General}

Seismic design of storage tanks is a wide research field, developing from the 1930s up to present day with many unsolved problems. To get basic concepts of seismic behavior of tanks one shall refer to classic studies of Housner [15,16], Haroun [17-19], Veletsos [2022], Malhotra [23-26], Nikolaenko [27-29] and so on. Review on main works, concerning the seismic design of storage tanks, was given in [30]. Some recent studies examine problems of seismic design of large LNG tanks [31-37], however, neglecting effects of loose insulation. Issa et al [38] explore the effects of compaction of perlite insulation for double-wall cryogenic vessels, used in NASA for storage of liquid hydrogen. It was concluded that the effects of dynamically-induced compaction are relatively small. However, vessels examined there were much smaller than tanks, considered in this paper. Zhang et al [39] examined the seismic effect of perlite insulation with density around 2000 $\mathrm{kg} / \mathrm{m}^{3}$ on the behavior of large LNG tanks, assuming a rigid connection between inner and outer tank. This assumption, however, seems to be incorrect, as far as even compacted perlite allow further deformation.

Seismic effects of perlite insulation may take several following forms:

1) horizontal accelerations induced by the earthquake cause additional inertia forces in the perlite body, exerting on the wall of inner and outer vessels, and thus, resulting in an additional overturning moment;

2) compacted perlite may transfer load from the inner wall to the outer wall, resulting in "combined action" of the inner and outer tank;

3) nonlinear and hysteretic effects of perlite loose body cause additional material damping. This study does not contain any research of that effect. Eurocode 8. Part 4 [40] recommends value the of damping ratio for granular materials to be assumed equal to $10 \%$;

4) passive pressure, caused by movement of the wall towards the loose body, and active pressure, in a less extent, may influence on the form and frequencies of excited so-called "flexible" modes of coupled fluid-structure motion, associated with radial deformations of the wall. 


\subsection{Inertial loads}

Inertial loads, induced by horizontal accelerations can be estimated with the following procedure. LNG tank with perlite insulation between inner and outer vessels under horizontal acceleration may be described as tank, rotated 90 degrees around horizontal axis (Figure 4). Horizontal acceleration is divided into circumferential and radial components.

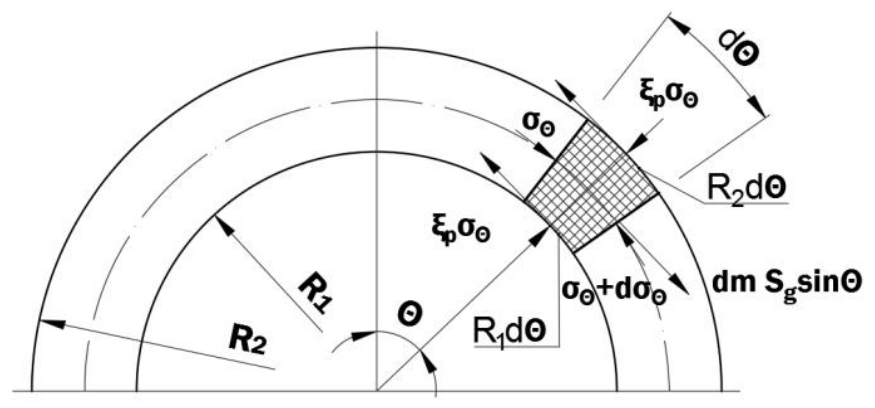

Fig. 4. Scheme to determine circumferential stress

Radial stress, induced by radial acceleration, may be obtained from:

$$
\sigma_{r, 1}=\rho(z) d_{p} S_{g} \cos \theta
$$

For the circumferential component for the scheme, given in figure 4, we obtain a linear differential equation of first order:

$$
\frac{d \sigma_{\theta}}{d \theta}+k \sigma_{\theta}=\rho(z)\left(\frac{R_{1}+R_{2}}{2}\right) S_{g} \sin \theta
$$

where

$$
k=\frac{\xi \operatorname{tg}\left(\varphi_{0}\right)\left(R_{1}+R_{2}\right)}{d_{p}}
$$

There, circumferential stress, obtained by solution of this equation $(0 \leq \theta \leq \pi)$ :

$$
\sigma_{\theta}(\theta)=\rho(z) S_{g}\left(\frac{R_{1}+R_{2}}{2}\right)\left[\frac{(k \sin \theta-\cos \theta)+e^{-k \theta}}{k^{2}+1}\right]
$$

To obtain radial stress, we sum stresses caused by both components:

$$
\sigma_{r}=\xi \sigma_{\theta}+\sigma_{r, 1}=\rho(z) S_{g} d_{p}\left(\frac{\xi}{2}\left(\frac{R_{1}}{d_{p}}+1\right)\left[\frac{(k \sin \theta-\cos \theta)+e^{-k \theta}}{k^{2}+1}\right]+\cos \theta\right)
$$

Thus, for the given tank with compacted perlite with density $58 \mathrm{~kg} / \mathrm{m}^{3}$ and relative compaction 1.09, maximum estimated seismic stress, exerted to the wall, for ground acceleration, equal to $0.25 \mathrm{~g} ; 0.5 \mathrm{~g}$ and $1 \mathrm{~g}$, reaches $0.17 \mathrm{kPa}, 0.34 \mathrm{kPa}$ and $0.68 \mathrm{kPa}$, 
respectively. These values are comparable or even greater than active pressure in operational conditions.

Therefore, seismic pressures must not be neglected.

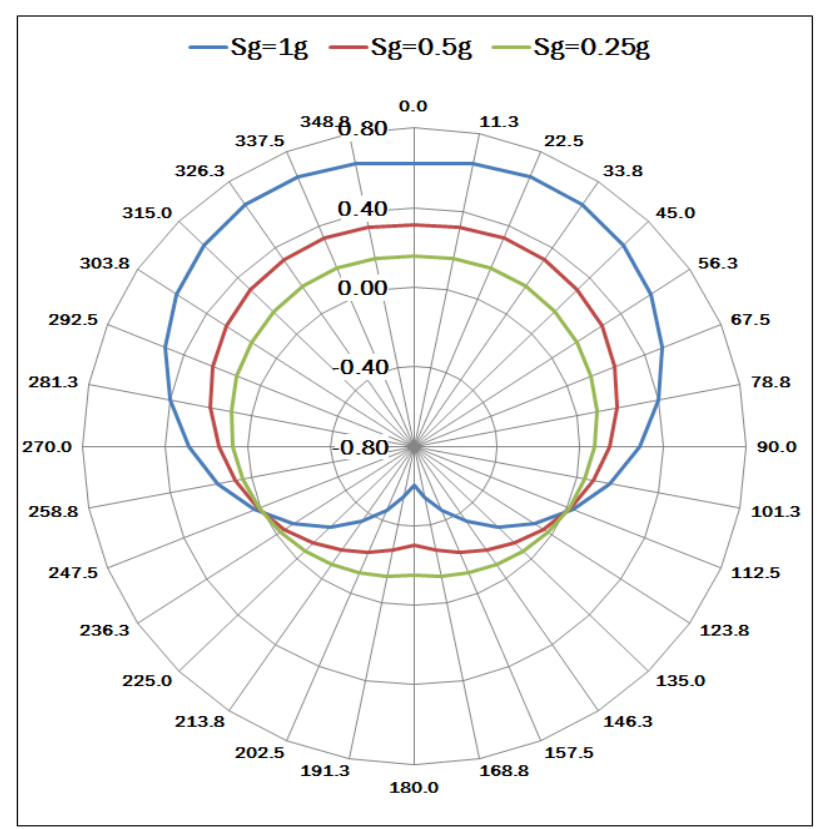

Figure 5. Seismic pressures due to perlite

\subsection{Effects of the perlite body on the dynamic characteristics of the inner tank}

To determine, whether load transfer occurs due to perlite, one should determine which state the perlite body is. It is quite obvious, that transfer occurs throughout the elastic body, and it is uncertain if it occurs in the loose body. Therefore, it should be found, if perlite becomes compacted enough due to seismic forces. This research will be conducted further. For the foregoing study, we assume that perlite body is in the compacted state.

It was shown in [20], that vertical pattern of excited modes of tank wall resemble modes of a cantilever beam. Therefore, to estimate the influence of compacted perlite backfilling on the dynamic characteristic of the tank we assume that tank wall can be replaced with a cantilever beam of unit width with thickness and length, equal to thickness and height of the wall, respectively. The first case is a free cantilever beam, and the second is a beam, supported on a Winkler foundation. Figure 6 shows, that presence of Winkler foundation with bed coefficient, estimated from the determined Young modulus of perlite, has significant influence on pattern excited modes. Also, it should be noted, that frequencies of the beam on a Winkler foundation are much higher than frequencies of the free cantilever beam. 


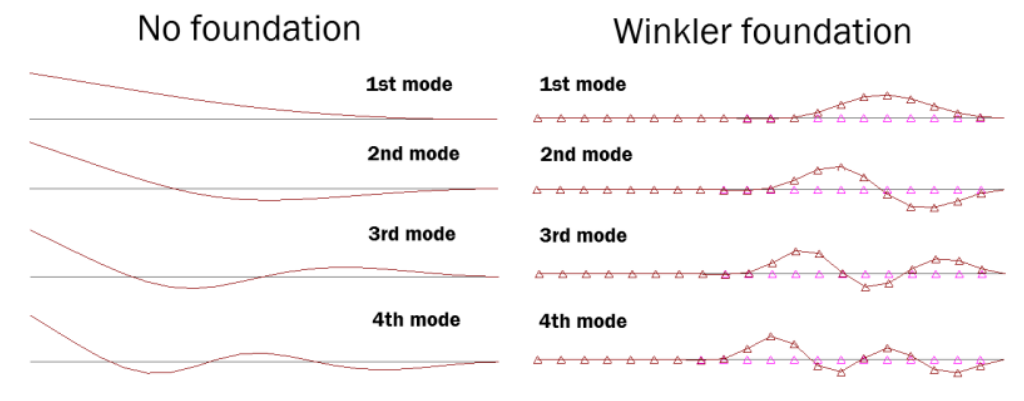

Fig. 6. Comparison of modes of analog cantilever beam modes

This analysis, however, is approximate and does not account features of shell physics, and does not include fluid-structure interaction. Therefore, there is a need for a solution of a coupled problem, including fluid-structure interaction.

Variational functional of fluid, excluding convective mode, takes form [41]:

$$
L(\varphi)=\int_{t_{1}}^{t_{2}}\left[\frac{\rho}{2} \int_{V}(\nabla \varphi \nabla \varphi) d V-\rho \int_{S_{2}}(\varphi \dot{w}) d S\right] d t
$$

where S2 means wall surface and $\varphi$ is the potential of fluid velocity.

Variational functional of structure takes form [15]:

$$
L_{s}=\int_{\tau_{1}}^{\tau_{2}}(\mathrm{~T}-\Pi+W) d \tau
$$

where $\mathrm{T}$ is the kinetic energy of shell, $\Pi$ is the strain energy of shell and $W$ is the work, done by external forces. Last can be divided into two parts - work, done by hydrodynamic pressure, and work, done by perlite pressure. Therefore, functional for a coupled problem takes form:

$$
\Lambda=\int_{\tau_{1}}^{\tau_{2}}\left(\mathrm{~T}-\Pi+\left[\frac{\rho}{2} \int_{V}(\nabla \varphi \nabla \varphi) d V-\rho \int_{S_{2}}(\varphi \dot{w}) d S\right]+W_{p}\right) d \tau
$$

where $\mathrm{W}_{\mathrm{p}}$ means the work, done by horizontal perlite pressure.

The problem of stationarity of this functional requires further research.

\section{Conclusions}

As a result of the research it was found that the active pressure of perlite should be calculated with respect to the effect of compaction. Increase of active pressure, obtained with consideration of compaction, is up to $7-12 \%$, which is within the allowable range of a safety factor of 1.3 , given in [13].

Passive pressures can be estimated from experimentally taken stress-strain curves for the case of compression without any possible lateral expansion. It is found that the compacted perlite can act as a linear body with Young modulus of about $500 \mathrm{kPa}$. To provide necessary level of safety of tank wall passive pressures should be accounted in the design of wall.

The inertial loads from the perlite body, induced by seismic action, can be comparable or can even exceed the active pressure. Due to the low strength of cylindrical shells to 
external pressures, this fact can lead to buckling of walls of empty tanks or upper layers of filled tanks, which adversely affects reliability and safety.

Approximate estimation of effects of insulation on excited modes of the empty tank was made for compacted state of perlite with analogy beam model. It was concluded that beam model modes were influenced by the presence of perlite backfilling, therefore, a further research is strictly required.

Several tasks are set for a further research:

- It is needed to determine, whether perlite can become compacted due to seismic loads and allow load transfer from inner tank to outer tank,

- The variational formulation of coupled "fluid-structure" problem, supplemented by the term, considering external perlite pressure, was set. The problem of stationarity of this functional will be solved in further study. A solution of this problem can help to find how the presence of perlite insulation influence on form and frequencies of excited "flexible" modes,

- Damping level for the perlite loose body needs to be estimated.

Thus, the objective of the study of influence of perlite loose insulation on the seismic behavior of low-temperature tanks is relevant and will improve the level of safety of structures and facilities with the high level of responsibility.

\section{References}

1. R. R. Shigapov and O. A. Kovalchuk, J. Seysmostoikoe stroitelstvo. Bezopasnost sooruzheniy, 1, 14-19 (2018)

2. R. R. Shigapov and O. A. Kovalchuk, J. Seysmostoikoe stroitelstvo. Bezopasnost sooruzheniy, 2, 46-52 (2018)

3. J. I. Chang and C.-C. Lin, Journal of loss prevention in process industries 19, 51-59, (2006)

4. G. C. Manos and R. W. Clough Earthquake engineering and structure dynamics, 13, 449-466, (1985)

5. Zama et al., Proceeding of 15 World Conference on Earthquake Engineering, 2428, 110 (2012)

6. B. Long and B. Garner, Guide to storage tanks and equipment ( JohnWiley\&Sons, 2004)

7. B. Popovskiy and A. Myler, Construction of low-temperature tanks (Moscow, Nedra, 1988)

8. Body of Rules 14.13330, Seismic building design code (Moscow, CPP, 2018)

9. Body of Rules 16.13330, Steelstructures (Moscow,CPP, 2017)

10. Standard of organization STO-SA-03-002-2009, Design rules, manufacture and installation of vertical cylindrical steel tanks for oil and petroleum products (Moscow, Rostehexpertiza, 2009)

11. Standard A. P. I. 620, Design and Construction of Large, Welded, Low-pressure Storage Tanks (Washington D.C., American Petroleum Institutep, 2013)

12. G. K. Klein, Structural mechanics of loose bodies (Moscow, Stroyizdat, 1977)

13. Body of Rules 43.13330, Construction of the industrial enterprises (Moscow, CPP, 2012)

14. B. M. Shoihet, Filling thermal insulation of double-walled isothermal tanks for the storage of liquefied gases: PhD thesis (Moscow, Teploproekt, 1984)

15. G. W. Housner, Bull. Seismol. Soc. Am., 47, 15-35 (1957)

16. G. W. Housner, Earthquakes Pressures on Fluid Containers, 26535 (1954)

17. M. A. Haroun and G. W. Housner, J. Appl. Mech., 48, 411-418 (1981)

18. M. A. Haroun and G. W. Housner, J. Eng. Mech. Div., 108, 783-800 (1982) 
19. M. A. Haroun, Earthq. Eng. Struct. Dyn., 11, 179-206 (1983)

20. A. S. Veletsos and J. Y. Yang, Advances in Civil Engineering through Engineering Mechanics (Raleigh: American Society of Civil Engineers, 1977)

21. A. S. Veletsos and Y. J. Tang, Struct. Eng., 112, 1228-1246 (1986)

22. A. S. Veletsos, American Society of Civil Engineers, ASCE, 255-370, (1984)

23. P. K. Malhotra and A. S. Veletsos, J. Struct. Eng, 120, 3471-88 (1994)

24. P. K. Malhotra and A. S. Veletsos and H. T. Tang, Proceedings of SMiRT12 (Stuttgart, Germany, 1993)

25. P. K. Malhotra, T. Wenk and M. Wieland, Struct. Eng. Int., 3, 197-201 (2000)

26. P. K. Malhotra and A. S. Veletsos, J. Struct. Eng., 120, 489-505 (1994)

27. N. A. Nikolaenko and S. V. Ulyanov, Statistical dynamics of engineering constructions (Moscow, Mashinostroenie, 1977)

28. I. I. Goldenblat et al., Recommendations for the calculation of tanks and gasholders for seismic effects (Moscow, Stroyizdat, 1969)

29. I. I. Goldenblat snd N. A. Nikolaenko, Calculation of structures for the action of seismic and impulsive forces (Moscow, Gosstroyizdat, 1961)

30. R. R. Shigapov and O. A. Kovalchuk, Vestnik Moscow State University Of Civil Engineering, 1, 53-62 (2017)

31. I. P. Christovasilis and A. S. Whittaker, Earthq. Spectra, 24, 599-616 (2008)

32. J.-R. Cho et al., KSME Int. J., 14, 633-644 (2000)

33. B. M. Jin et al., Proccedings of 13th, World Conference on Earthquake Engineering, 1341, 43-57 (2004)

34. M. K. Kim et al., Soil Dyn. Earthq. Eng., 22 (9-12),1151-58 (2002)

35. A. Tsouvalas and A.V. Metrikine, Int. J. Earthq. Impact Eng, 1, 98-130 (2016)

36. Marcus N. T. Gillard et al., Proc. Inst. Civ. Eng.- Eng. Comput. Mech., 165, 49-56, (2012)

37. E. P. Zavadskaya and O. A. Kovalchuk, Vestnik Belgorod State Technical University, 12 65-70 (2016)

38. C. A. Issa, J. F. Peters, E. W. Jones, Int. J. Press. Vessel. Pi., 64, 51-65 (1995)

39. R. Zhang and D. J. Weng, Loss Prev. Process Ind. Elsevier Ltd., 30, 9-16 (2014)

40. Eurocode 8 EN 198-4, Design of structures for earthquake resistance-Part 4 : Silos, tanks, and pipelines (Brussels, Belgium, European committee for Standardization, 2006)

41. H. H. Hsiung and V. I. Weingarten, Report USCCE, 013, (1973). 